\title{
The Effect of IPad on School Preparedness among Preschool Children with Hearing-Impairments
}

\author{
Maryam Hafez Turkestani ${ }^{1}$ \\ ${ }^{1}$ Special Education Department, College of Education, King Saud University, Saudi Arabia \\ Correspondence: Maryam Hafez Turkestani, Special Education Department, College of Education, King Saud \\ University, Saudi Arabia. Tel: 966-505-165-919. E-mail: maryamturkestani@gmail.com
}

Received: May 5, 2015 Accepted: June 15, 2015 Online Published: October 27, 2015

doi:10.5539/ies.v8n11p50 URL: http://dx.doi.org/10.5539/ies.v8n11p50

\begin{abstract}
With modern technological developments and with the fast expansion of mobile technical equipment, conducting a field study to find out how technology influences various developmental aspects of normal and special needs children at the preschool stage was deemed appropriate and timely hearing impairment. In this study aimed at finding out the effect of iPad on school preparedness among school children with hearing impairment. In this study, the children attended the national kindergarten in Al-Riyadh. The study sample was divided into control (7) and experimental (8) groups. Children in the experimental group used the iPad for 15 weeks. Results showed improvement of the experimental group in all measured areas. The control group, those who did not use the iPads, improved in both their kinetic and social areas. In addition, differences were found between groups on post measurement favoring experimental group. The study recommended conducting more experimental and longitudinal studies to further delve into the effects of using iPads in preschools with children who have impaired hearing.
\end{abstract}

Keywords: effect, iPad, school preparedness, hearing-impairment, preschool children, Saudi Arabia

\section{Introduction and Background}

The early years of a child's life is a decisive stage, for they are the basis on which successive developmental stages are formed. These stages involve the creation of his or her personality, traits and attitudes as well as the child's physical, mental, social and psychological development. During these years, children begin to understand basic concepts and acquire learning skills (Al-Hashmi \& Abdel-Razzaq, 2012; Saleh, 2012). Because this stage plays such a critical role in the future achievement of a child, it may be possible to predict the level of a child's success at school at a later time by analyzing his social, emotional and mental skills during his or her preschool years (Burgess, 2005).

A child in school must have appropriate and effective social, mental, kinetic, and lingual development in order to learn the necessary skills of reading, writing and mathematics. Studies indicate that the main factors influencing a student's preparedness for learning these skills stem from the developmental stages (Awwad, 1998).

Borgess (2005) and Awwad (2001) identified a number of basic factors that overlap with each other to form a child who is ready for school entry, including his or her mental, physical, personal, and lingual readiness. Kinetic readiness refers to the child's ability to have specific and large movements.

Lingual readiness refers to a child's degree of lingual development that allows him to participate and interact in the school and express himself. Children must have a certain development of lingual and speech skills to qualify them to enter school (Abu-Ma'al, 1996).

The child needs also some level of mental abilities that enable him to start school such as sequencing, developing wrong and right concepts, and solving simple problems (Mohammad \& Mahmoud, 2003). The child who does not reach this certain developmental stage of appropriate mental ability is not likely to accomplish school requirements that require ideas.

In addition, emotional and social readiness is represented in the child's psychological wellbeing, emotional stability and social skills. These skills help him or her communicates and interacts with others and creates healthy relationships within the school environment (lberts \& Jesler, 1996). 
For hearing-impairment children as well for unimpaired children, their time in preschool is a transitional stage between previous developmental stages and the next developmental ones. Hearing-impairment children in their early stages need a change of activities with verbal characteristics as well as tangible experiences, such as pictures, drawings and illustrative shapes (Saleh, 2012). They are also in need of games and activities in which tangible, kinetic, visual, and audio activities are consolidated (Saleh, 2012).

Hearing-impairment children are characterized with continuous movement around the classroom in order to get closer to sound sources (Marshark, 1997, Halawah \& Abdo, 1996; Hanafi, 2003). These researchers (Marshark, 1997, Halawah \& Abdo, 1996; Hanafi, 2003) believe that hearing-impairment children go through the same developmental stages as normal children; there are no apparent differences with regard to physical development and requirement.

Al-Khateeb (2002) pointed out that more than 150 published studies during the last fifty years on speech skills in hearing-impairment children show that the effects of this disability on language development vary greatly. The ultimate conclusion is that a hearing-impairment may have only a small effect on speech and language for the majority of those with this impairment. Abdel-Muti (2000) indicated that the children with hearing-impairment out performed those without impairments in some cognitive strategies such as slow mental analysis, while non-impaired children outperformed hearing-impairment children in successive mental analysis.

When studying hearing-impairment child psychology, two main views are found. One view sees unique psychological characteristics of hearing-impairment children that are different from those of other special needs categories. The other view is that many of the scientific studies of children with hearing impairments did not reach conclusive results indicating the existence of a specific psychology for hearing-impairment children.

Abdel-Wahed (2001) pointed out that children with hearing-impairment have an inability to communicate with others, which affects their linguistic, cognitive, and social development due to social and psychological pressures facing them. River (2009) asserted, in general, that hearing-impairment children must, during the preschool stage, respond to visual and physical environmental interactions and learn from the atmosphere in which they live.

The above review identifies the different influences hearing- impaired children have on different developmental aspects (kinetics, cognitive, linguistic, psychological and social aspects). These differences depend on the relationship between different hearing-disability specific developmental aspects and how hearing affects the development of these aspects.

Caring for the disabled in the Arab world and in Saudi Arabia is one of the areas gaining most interest, on either the research level or educational level. However, it is highly dependent on age, since these categories have many urgent problems to overcome. The creation of multiple techniques and approaches for the treatment of these problems in order to help the development of a child's abilities and personality is the result (Mohammad, 2007).

\subsection{Research Problem}

There is a great debate over the effect of using electronic devices to aid the development of children (Green \& Bavelier, 2006). Today, while living in the multiplicity of the electronic technology age, we cannot ignore the role of these devices in raising our children and it is evident that there is a large effect of these devices on various developmental characteristics of children.

Different studies' results have shown the effect of using computers and electronic games on various aspects that affect a child's level of preparedness for school (Khasawneh \& Al-Awidi, 2008; Hatzigianni \& Margetts, 2012; Green \& Bavelier, 2006; Spence \& Feng, 2010; Chisholm, Hickey, Subrahmanayam, \& Greenfield, 1994; Mcclanahan, 2012; Hatzigianni \& Margetts, 2012; Kingstone, 2010).

On the other hand, other researchers reviewed negative effects of technology. Rosen, Whaling, Carrier, Cheever, and Rockhum's (2013) study confirmed that children who are accustomed to concentrating on many tasks in electronic programs suffer from lack of concentration with study materials.

With the advancement of technological devices and the increase of portable computers, the need for deeper investigation into the social, cultural and political effects on both individual and societal levels must increase (Al-Mehsen, 2003). Because technology is now varied and renewable, there is a need for more Arabic studies aiming to shed light on the importance of these technological devices and what role they can play for children with special needs. This study focused on those with hearing impairments.

The researcher noticed the scarcity of Arabic and Saudi Arabian studies addressing the discovery of IPad usage and its influence on various developmental aspects of children with special needs, particularly hearing-impairment children. Therefore, the current research investigated whether the use of iPads in preschools 
influence the preparedness of hearing-impairment children with hearing- impairments for school.

\subsection{Significant Previous Studies}

Several studies suggested that individuals with a hearing impairment in different age groups benefit greatly from using computers and different electronic devices (Passig \& Eden, 2000; Eden, 2008; Alimam \& AL-Abbad, 2010). Passig and Eden's (2000) study, for example, aimed at developing creative thinking skills. This study divided children into two groups, the experimental (children with hearing impairments) and control (children without hearing impairments) group. The results showed an improvement in elastic flexible thinking skills among the experimental group.

Eden (2008) conducted a study on 69throughhearing-impairment ten year-olds with hearing impairments that looked at the efficiency of using virtual status technology (i.e. unreal situations) in an interactive environment. This technology helped in teaching children with hearing-impairments to organize chronological events logically and assisted with chronological perceptions. Results showed the efficiency of virtual reality on the children's ability to organize chronological events.

To find the influence of electronic games in developing creative thinking skills among 65 individuals with hearing impairments, Al-imam and Al-Abbad (2010) divided them into 32 experimental and 33 control groups; results showed the influence of electronic games on some creative thinking skills, such as analysis, synthesis, and taking decisions.

Awwad and Abdela-Rahman (2004) conducted a study to find out the influence of educational computer games on information classification among 22 deaf males and females. Results showed that these games which focus on classifying items like colors, animals, shapes etc., do influence development of classification skills among students who are deaf.

Another study conducted by Sharadgha (2011) was aimed at learning the influence of educational computer programs on the speech abilities of students with hearing impairments. They were divided into 15 experimental and 15 control groups. Results showed statistically significant differences in favor of the experimental group as well as differences on language expressions depending on the age of the subject.

Morsi (2013) conducted a study on the efficiency of various stimuli from computer programs on study achievement among children with hearing impairments. These children were at the preparatory stage in Egypt and the study was conducted on 24 students divided into 3 groups; the first experimental group was taught through the use of moving pictures with intense patterns. The second experimental group was taught through fixed picture intensity, and the single control group was taught the same unit with traditional methods. The results showed superiority for the first experimental group, followed by the second experimental group, with significant differences between them and the control group.

The above review shows that previous studies focused on finding out the influence the computers have on various developmental aspects, but the researcher could not find any Arabic or Saudi studies examining the influence of using smart technological devices on school preparedness for children with hearing impairments at the preschool stage.

\subsection{Research Terms}

School readiness: refers to a latent ability in the child that enables him or her to learn and acquire skills and experiences quickly and easily. It depends on the existence and efficiency of the healthy physical, mental, psychological and social maturation of the child (Awwad, 1999).

The researcher defines it as the physical, cognitive, linguistic, affective and social readiness so the child can be ready to acquire basic needed skills for school. These skills must be acquired at the preschool stage to facilitate his or her later academic life. Procedurally, it is defined as scores gained by a child in a survey test for preschool children (this test focuses on the kinetic, linguistic, cognitive, affective and social aspects of a child).

A child with a hearing-impairment: is defined with shortage or loss in the hearing sense (he or she can hear more than 27 decibel, but less than 70), which necessitates the use of aiding tools in order to hear speech (Sisalem, 2002).

\subsection{Research Objective}

This study aimed at finding out the effectiveness of using iPads on preparing children with hearing impairments for school. 


\subsection{Research Significance}

The current study is significant according to a number of reasons; first, the scarcity of Arabic and Saudi studies on this particular topic. Second, the enrichment of educational literature, shedding light on the way of children's development and how they can achieve success in order to enter school. Third, the findings that may highlight the role of technology in preparing children with hearing impairments to enter school and what challenges they may face. These findings could pave the way for designing early intervention programs. Finally, this study might pave the way for educators and those in charge of teaching hearing-impairment children to educate through portable iPads during the early childhood stages.

\subsection{Research Hypotheses}

The current study was designed to accept or refuse the following hypotheses:

- There are statistically significant differences between mean ranks of school readiness (total score and subdomains: kinetic, linguistic, cognitive and affective, social) between pre and post measurement for the experimental group which is 8 children with hearing impairments.

- There are no statistically significant differences between mean ranks of school readiness (total score and subdomains kinetic, linguistic, cognitive, affective, social) between pre and post measurement for the control group which is 7 children with hearing impairments.

- There are statistically significant differences between mean rank of school readiness (total score and sub domains: kinetic, linguistic, cognitive, affective, social) between post-measurements for both experimental and control group.

- No statistically significant differences between mean ranks of school readiness (total score and subdomains kinetic, linguistic, cognitive, affective, social) between males and females in the experimental group at post-measurement.

\section{Methodology and Procedures}

\subsection{Methodology}

To test the hypotheses' validity which tried to prove that there are statistically significant differences between mean ranks of school readiness (total score and subdomains: kinetic, linguistic, cognitive and affective, social) between pre and post measurement for the experimental group which is 8 children with hearing impairments, the Wilcoxon test was used in order to determine significant differences between the experimental and control group for the pre- and post-administration scores in sub dimension and the total score of the school readiness test. The experimental approach (design) was used in which pre-measurement and post-measurement are made for the experimental and control groups of children with hearing impairments.

\subsection{Research Sample}

The study was carried out on a sample of 15 students with hearing-impairments ranging in age from4-6 years old, of which 8 were in the experimental group and (7) were in the control group. All of the sample members' intelligence degree reported to be between 95 and 100. Their hearing deficiency ranged from 40 to 65 decibels and all were using hearing aids. They had no previous experience with the internet and their families have no computer at home.

\subsection{Instruments}

First: Kuwait survey test of preschool children (2003)

The Kuwait survey test of preschool children is a standardized test for children aged 3-6 years and is administered individually in 20 minutes. It is used to find a child's developmental state in some important domains such as kinetic, linguistic, cognitive, affective, social skills in order to find his level of preparedness for school. This test has two versions, one for 3-4.5 year olds, and the other for 4.5-6 year olds; the latter version was used in this study. This test measures 4 basic domains. Table 1 shows the Kuwait survey test of preschool children (2003) domains and their concerns. 
Table 1. The Kuwait survey test of preschool children (2003) domains and their concerns

\begin{tabular}{|c|c|}
\hline Domain & Concerns \\
\hline Motor domain & Large, accurate motor skills and kinetic balance. \\
\hline $\begin{array}{l}\text { Language } \\
\text { domain }\end{array}$ & $\begin{array}{l}\text { Retrieving words, sentences, numbers, and meanings as well as understanding language } \\
\text { expressions. }\end{array}$ \\
\hline $\begin{array}{l}\text { Cognitive } \\
\text { domain }\end{array}$ & Child's ability to gain information using numbers, pictures and problem solving. \\
\hline Cognitive & Child's ability to gain information using numbers, pictures and problem solving. \\
\hline Affective/social & Estimating consistent behavior from the teacher or a parent measured by a scale of 32 items. \\
\hline
\end{tabular}

- Motor domain involves large, accurate motor skills and kinetic balance.

- Language domain is concerned with retrieving words, sentences, numbers, and meanings as well as understanding language expressions.

- Cognitive domain is interested in measuring a child's ability to gain information using numbers, pictures and problem solving.

- Affective/social domain is concerned with estimating consistent behavior from the teacher or a parent measured by a scale of 32 items.

To check the scale validity and reliability, it was administered on 22 children with hearing impairments at the kindergarten in Al-Riyadh and each item of the scale coordinated with the domain's total score. This score was computed and results are displayed in Table 2 .

Table 2. Items correlation coefficients for (motor, language, cognitive) of the scale with total score of their respective domain $(\mathrm{N}=22)$

\begin{tabular}{lcccccc}
\hline Dimension & $\mathrm{m}$ & $\mathrm{R}$ & $\mathrm{m}$ & $\mathrm{r}$ & $\mathrm{m}$ & $\mathrm{R}$ \\
\hline \multirow{4}{*}{ Motor } & 1 & $* * 0.5681$ & 5 & $* * 0.6148$ & 9 & $* * 0.6231$ \\
& 2 & $* * 0.6478$ & 6 & $* * 0.8782$ & 10 & $* * 0.5782$ \\
& 3 & $* * 0.6441$ & 7 & $* * 0.8094$ & 11 & $* * 0.8133$ \\
& 4 & $* * 0.5416$ & 8 & $* * 0.7589$ & & \\
Language & 1 & $* 0.4736$ & 4 & $* 0.4462$ & 7 & $* * 0.6490$ \\
& 2 & $* * 0.6908$ & 5 & $* * 0.5732$ & 8 & $* * 0.6176$ \\
& 3 & $* * 0.6084$ & 6 & $* * 0.6384$ & 9 & $* * 0.7674$ \\
& 1 & $* 0.4771$ & 6 & $* 0.4554$ & 11 & $* * 0.7735$ \\
Cognitive & 2 & $* 0.4320$ & 7 & $* * 0.6061$ & 12 & $* 0.6261$ \\
& 3 & $* 0.4361$ & 8 & $* 0.4596$ & 13 & $* 0.4324$ \\
& 4 & $* * 0.7735$ & 9 & $* 0.4761$ & & \\
\hline
\end{tabular}

*sig. at $\alpha=0.05$.

$* *$ sig. at $\alpha=0.01$.

The above table shows that all correlation coefficient values were significant at the $(0.05)$ and $(0.01)$ level. At the same time, Table 3 shows the correlation coefficients of each domain with the total score. 
Table 3. Correlation coefficients of the scale's three dimension with total score ( $\mathrm{N}=22)$

\begin{tabular}{llc}
\cline { 2 - 2 } Dimension & Correlation coefficient \\
\cline { 2 - 3 } Motor & $* * 0.8794$ \\
Language & $* * 0.8544$ \\
Cognitive & $* * 0.6485$ \\
\hline
\end{tabular}

$* * \operatorname{sig}$ at $\alpha=0.01$.

This table showed that all correlation coefficients of each domain with the scale total score were significant at $\alpha=0.01$. The researcher also computed correlation coefficients for each item with its domain's total score, as shown in Table 4.

Table 4. Items correlation coefficients of affective / social domain with domains total score ( $\mathrm{N}=22)$

\begin{tabular}{lcccc}
\hline Dimension & $\mathrm{m}$ & Correlation coefficient & $\mathrm{m}$ & Correlation coefficient \\
\hline \multirow{3}{*}{ Affective } & 1 & $* * 0.5504$ & 5 & $* * 0.6387$ \\
& 2 & $* 0.4846$ & 6 & $* * 0.5503$ \\
& 3 & $* * 0.6386$ & 7 & $* 0.4834$ \\
Social & 4 & $* 0.5356$ & 8 & $* * 0.4832$ \\
& 9 & $* 0.4834$ & 12 & $* * 0.5979$ \\
Communication & 10 & $* 0.4527$ & 13 & 0.7885 \\
& 15 & $* * 0.5912$ & 19 & $* * 0.7051$ \\
& 17 & $* * 0.7345$ & 20 & $* 0.4773$ \\
& 18 & $* * 0.8086$ & & $* * 0.6366$ \\
Personality & 22 & $* 0.4447$ & 28 & $* 0.4521$ \\
& 23 & $* 0.4957$ & 29 & $* 0.4556$ \\
& 24 & $* 0.5194$ & 30 & $* 0.4447$ \\
& 25 & $* 0.4567$ & 31 & $* * 0.6667$ \\
& 26 & $* 0.4282$ & 32 & $* 0.5184$ \\
& 27 & $* 0.4528$ & & \\
\hline
\end{tabular}

* Significant at 0.05 level.

** sig at 0.01 level.

Table 4 shows that all correlation coefficients were significant at ( 0.05 and 0.01$)$ levels. The researcher computed correlation coefficients for each domain score with the total score, as shown in Table 5.

Table 5. Correlation coefficients of affective/social domain of the scale with total score $(\mathrm{N}=22)$

\begin{tabular}{ll}
\hline Dimension & Correlation coefficient \\
\hline Affective & $* 0.4670$ \\
Social & $* 0.4571$ \\
Communication & $* 0.46941$ \\
Personality & $* * 0.7531$ \\
\hline
\end{tabular}

* Significant at 0.05 level.

** sig at 0.01 level. 
Table 5 shows that all correlation coefficient values were significant at $(\alpha=0.05$ and 0.01$)$, meaning that there is an availability of acceptable, reliable coefficients for the scale among children with hearing impairments. Lastly, to check for scale reliability for children with hearing-impairments, Cronbach alpha was computed and Table 6 displayed these results.

Table 6. Cronbach alpha of the scale dimensions $(\mathrm{N}=22)$

\begin{tabular}{lcc}
\hline Dimension & items & Cronbach alpha \\
\hline Motor & 11 & 0.90 \\
Language & 9 & 0.80 \\
Cognitive & 13 & 0.69 \\
First three dimensions of & 33 & 0.90 \\
the scale & 8 & 0.37 \\
Affective & 6 & 0.42 \\
Social & 7 & 0.76 \\
Communication & 11 & 0.49 \\
Personality & 32 & 0.54 \\
Affective Social to Scale & & \\
\hline
\end{tabular}

From Table 6, it can be seen that the scale was valid and reliable, so it was deemed appropriate to use with children who have poor hearing.

Second: the iPads

IPads were used in this study; this device was selected because of its characteristics, such as its simplicity. Saylor and Gil (2012) presented many characteristics of the iPad; it has an attractive look and its applications could be easily accessed. Furthermore, several applications can be loaded for free, which provide the child with many opportunities and these applications can be used anywhere at any time (Hutehinson et al., 2012; Melhusish \& Fallon, 2010). Many of its applications are already in line with teaching at the early childhood stages (Bainster, 2010; Couse \& Chen, 2010; Cubelic \& Larwin, 2014). For achieving study objectives, a collection of games from the application store was downloaded.

\subsection{Procedures}

The following procedures were followed:

- Attaining the agreement of the ministry of education to enter kindergarteners for this study and contact mothers inside the kindergarten.

- Choosing a convenient sample under criteria specific to the sample.

- Getting written consent from the parents to allow the hearing-impairment children to participate in the study.

- Meeting with children and getting their consent for participation in the study.

- Administering the Kuwait survey test for preschoolers on individual hearing-impairment children and recording results.

- Assigning children randomly into experimental and control groups.

- Distributing IPads for the experimental group at the beginning of the experiment.

- Granting IPads for the control group at the end of the experiment as a reward of their participation.

To check the equivalence of groups, the Mann-Whitney test was administered and results are displayed in Table 7 . 
Table 7. Mann-Whitney test of differences between mean rank scores of experimental and control group at pre administration of school readiness

\begin{tabular}{llllllll}
\hline Dimensions & Groups & $\mathrm{N}$ & Mean ranks & Sum ranks & U value & Sig. level & Notes \\
\hline \multirow{2}{*}{ Motor } & Control & 7 & 7.86 & 55.00 & \multirow{2}{*}{27.000} & \multirow{2}{*}{0.907} & Non sig \\
& Exper. & 8 & 8.13 & 65.00 & & & \\
Language & Control & 7 & 9.07 & 63.50 & \multirow{2}{*}{20.500} & 0.375 & Non sig \\
& Exper. & 8 & 7.06 & 56.50 & & & \\
Cognitive & Control & 7 & 7.64 & 53.50 & \multirow{2}{*}{25.500} & 0.771 & Non sig \\
& Exper. & 8 & 8.31 & 66.50 & & & \\
Affective /social & Control & 7 & 7.50 & 52.50 & \multirow{2}{*}{24.500} & 0.685 & Non sig \\
Total score & Exper. & 8 & 8.44 & 67.50 & & & \\
School readiness & Control & 7 & 8.07 & 56.50 & \multirow{2}{*}{27.00} & 0.654 & Non sig \\
\hline
\end{tabular}

Table 7 showed that $U$ values were not significant in motor, language, cognitive, affective/social dimensions. The total score, meaning the results of both the experimental and control groups scores at pre-administration, were not different. Through this, the group's equivalency was established.

\subsection{Statistical Techniques}

Spearman correlation coefficients were used to determine the pictured self-concept scale validity Cronbach alpha and the Mann-Whitney test were used for establishing reliability.

\section{Results}

To test the hypothesis (1) which stated that there are statistically significant differences between mean ranks of school readiness (total score and subdomains: kinetic, linguistic, cognitive and affective, social) between pre and post measurement for the experimental group which is 8 children with hearing impairments, the Wilcoxon test was used in order to determine significant differences between the experimental and control group for the preand post-administration scores in sub dimension and the total score of the school readiness test. Table 8 displays these results:

Table 8. Wilcoxon test of significance differences between mean rank score at pre administration and post administration scores for the experimental group

\begin{tabular}{|c|c|c|c|c|c|c|c|}
\hline Dimensions & Groups & $\mathrm{N}$ & mean rank & Sum rank & $Z$ value & Sig level & Notes \\
\hline \multirow{3}{*}{ Motor } & Post $<$ pre & 0 & 0.00 & 0.00 & & & \\
\hline & Post $>$ pre & 8 & 4.50 & 36.00 & -2.555 & 0.011 & Significant \\
\hline & Post $=$ pre & 0 & & & & & \\
\hline \multirow{3}{*}{ Language } & Post $<$ pre & 0 & 0.00 & 0.00 & & & \\
\hline & Post $>$ pre & 8 & 4.50 & 36.00 & -2.536 & 0.011 & Significant \\
\hline & Post $=$ pre & 0 & & & & & \\
\hline \multirow{3}{*}{ Cognitive } & Post $<$ pre & 0 & 0.00 & 0.00 & & & \\
\hline & Post $>$ pre & 8 & 4.50 & 36.00 & -2.536 & 0.011 & Significant \\
\hline & Post $=$ pre & 0 & & & & & \\
\hline \multirow{3}{*}{ Affective/ social } & Post $<$ pre & 0 & 0.00 & 0.00 & & & \\
\hline & Post $>$ pre & 8 & 4.50 & 36.00 & -2.524 & 0.012 & Significant \\
\hline & Post $=$ pre & 0 & & & & & \\
\hline \multirow{3}{*}{ Total score } & Post $<$ pre & 0 & 0.00 & 0.00 & & & \\
\hline & Post $>$ pre & 8 & 4.50 & 36.00 & -2.524 & 0.012 & Significant \\
\hline & Post $=$ pre & 0 & & & & & \\
\hline
\end{tabular}


Table 8 showed that the $\mathrm{Z}$ value for motor, language, cognitive and affective/social dimensions was significant, as well as the total score of the school readiness scale. These differences were for post-administration, so our first hypothesis is confirmed and accepted.

To test the second hypothesis which stated that there are statistically significant differences between mean rank of school readiness (total score and sub domains: kinetic, linguistic, cognitive, affective, social) between post-measurements for both experimental and control group, the Wilcoxon test was also used and results are displayed in Table 9.

Table 9. Wilcoxon test for significance differences between mean score of pre administration and post administration for control group in school readiness scale

\begin{tabular}{llllllll}
\hline Dimensions & Groups & $\mathrm{N}$ & mean rank & Sum rank & $\mathrm{Z}$ value & Sig level & Notes \\
\hline \multirow{3}{*}{ Motor } & Post $<$ pre & 7 & 4.00 & 28.00 & & & \\
& Post $>$ pre & 0 & 0.00 & 0.00 & -2.366 & 0.018 & Significant \\
& Post $=$ pre & 0 & & & & & \\
Language & Post $<$ pre & 1 & 1.50 & 1.50 & & & \\
& Post $>$ pre & 1 & 1.50 & 1.50 & 0.000 & 1.000 & Non Sig. \\
& Post $=$ pre & 5 & & & & & \\
Cognition & Post $<$ pre & 0 & 0.00 & 0.00 & & & \\
& Post $>$ pre & 0 & 0.00 & 0.00 & 0.000 & 1.000 & Non Sig. \\
& Post $=$ pre & 7 & & & & & \\
Affective/ social & Post $<$ pre & 7 & 4.00 & 28.00 & & & \\
& Post $>$ pre & 0 & 0.00 & 0.00 & -2.366 & 0.018 & Significant \\
& Post $=$ pre & 0 & & & & & \\
Total score & Post $<$ pre & 7 & 4.00 & 28.00 & & & \\
& Post $>$ pre & 0 & 0.00 & 0.00 & -2.371 & 0.018 & Significant \\
& Post $=$ pre & 0 & & & & & \\
\hline
\end{tabular}

Table 9 showed that the $\mathrm{Z}$ value was significant in motor and affective/social domains as well as in the total scale, whereas there was not a significant change in language and cognitive domains. These results suggest that there are statistically significant differences between mean score ranks of pre-administration and that of post-administration for the control group in motor, and affective/social domains as well as in the scale's total score. However, there were no significant differences in other subdomains were found. So, the second hypothesis is partially accepted for its total score, motor, language, cognitive and effective social domains.

To test the third hypothesis that stated there are statistically significant differences between mean rank of school readiness (total score and sub domains: kinetic, linguistic, cognitive, affective, social) between post-measurements for both experimental and control group, the Mann-Whitney test was used and Table 10 displayed its results. 
Table 10. Mann-Whitney test of differences significance between experimental and control group score ranks on the post administration of school readiness scale

\begin{tabular}{llllllll}
\hline Dimensions & Groups & $\mathrm{N}$ & Mean ranks & Sum ranks & U value & Sig. level & Notes \\
\hline \multirow{2}{*}{ Motor } & Control & 7 & 7.21 & 50.50 & 22.500 & Non sig \\
& expert & 8 & 6.69 & 69.50 & & \\
Language & Control & 7 & 4.00 & 28.00 & 0.000 & Sig. \\
& expert & 8 & 11.50 & 92.00 & & \\
Cognitive & Control & 7 & 4.14 & 29.00 & 1.000 & Sig. \\
& expert & 8 & 11.38 & 91.00 & & \\
Affective /social & Control & 7 & 4.00 & 28.00 & \multirow{2}{*}{0.000} & Sig. \\
Total score & expert & 8 & 11.50 & 92.00 & & Sig. \\
School readiness & Control & 7 & 4.00 & 28.00 & 0.000 & \\
\hline
\end{tabular}

Table 10 shows that the $\mathrm{U}$ value was significant in language, cognitive and affective/social as well as in total scale, suggesting statistically significant differences between the experimental group's mean score and that of the control group on the post-administration of the school readiness scale. They also differed in the total score, where the experimental group outperformed the control group. No such differences in motor dimension were found, suggesting there were no significant differences between the groups on the post-administration in motor dimension.

And finally, to test the fourth hypothesis that stated there are no statistically significant differences between mean ranks of school readiness (total score and subdomains kinetic, linguistic, cognitive, affective, social) between males and females in the experimental group at post-measurement, the Mann-Whitney test was used and results are shown in Table 11.

Table 11. Mann-Whitney test of significance differences in post administration of school readiness scale for experimental group by gender

\begin{tabular}{|c|c|c|c|c|c|c|c|}
\hline Dimensions & sex & $\mathrm{N}$ & Mean ranks & Sum ranks & $\mathrm{U}$ value & Sig. level & Notes \\
\hline \multirow{2}{*}{ Motor } & Male & 4 & 5.00 & 20.00 & \multirow{2}{*}{6.000} & \multirow{2}{*}{0.552} & \multirow{2}{*}{ Non sig } \\
\hline & female & 4 & 4.00 & 16.00 & & & \\
\hline \multirow{2}{*}{ Language } & Male & 4 & 3.13 & 12.50 & \multirow{2}{*}{2.500} & \multirow{2}{*}{0.099} & \multirow{2}{*}{ Non sig } \\
\hline & female & 4 & 5.88 & 23.50 & & & \\
\hline \multirow{2}{*}{ Cognitive } & Male & 4 & 5.50 & 22.00 & \multirow{2}{*}{4.000} & \multirow{2}{*}{0.131} & \multirow{2}{*}{ Non sig } \\
\hline & female & 4 & 3.50 & 14.00 & & & \\
\hline \multirow{2}{*}{ Affective /social } & Male & 4 & 4.25 & 17.00 & \multirow{2}{*}{7.000} & \multirow{2}{*}{0.770} & \multirow{2}{*}{ Non sig } \\
\hline & female & 4 & 4.75 & 19.00 & & & \\
\hline Total score & Male & 4 & 4.75 & 19.00 & \multirow{2}{*}{7.000} & \multirow{2}{*}{0.767} & \multirow{2}{*}{ Non sig } \\
\hline School readiness & female & 4 & 4.25 & 17.00 & & & \\
\hline
\end{tabular}

Table 11 shows that the $\mathrm{U}$ values were not significant in all scale dimensions as well as in the total scale, suggesting there were not significant differences in the experimental group scores due to their sex at post-administration. Thus, our fourth hypothesis is accepted.

\section{Discussion}

The previous review showed improved school readiness among the children in the experimental group who used iPad. Their scores in the post-measurement and in all domains increased while the scores for motor and social/affective domain increased for the control group. No such increases were found between the pre-and 
post-measurements in language, and cognitive domains. There were significant differences between groups, where the experimental group outperformed the control group in language, cognitive, and social/affective domains as well as in the total score. Furthermore, results showed improved performance of both groups in the motor dimension, but no statistically significant differences in their post-measurement; improvement was equal in these groups. These results were consistent with different results from other studies showing that computer and electronic games develop different mental aspects among the children with hearing impairments at various ages (Passig \& Eden, 2000; Perez, 2010; Gaad \& Qaryouti, 2002; Al Qaryouti, 2002; Awwad \& Abdel-Rahman, 2004; Shardaghah, 2011).

Therefore, the researcher believes that the iPad device provides children with hearing impairments with the opportunity to communicate visually through the information displayed on the screen. They are able to concentrate on visually perceiving, which is how children with hearing impairments largely communicate. It is one of the best learning channels for them because the iPad relies on visual means to display its information. Children with hearing impairments depend on their vision for obtaining different experiences. Moreover, when children use the iPad, it opens up new horizons, especially when they have previously used this device or have dealt with computers. Technology of this kind supports and enhances the development of various skills in kindergarten. Al-Jawaldeh and Suhail (2013) emphasized that these games contribute to the development of various skills among children with disabilities in addition to adding fun and enjoyment in the classroom. Al-Jaberi (2011) believed that modern technology provides children with new opportunities to independently learn, acquiring experimental discovery methods. Couse and Chen (2010) emphasized the ease that children deal with and adjust to using IPad computer technology.

The lack of improvement in the control group might be due to its complete dependence in teaching children at this stage only through verbal teaching. Children with hearing impairments may lose opportunities of listening to verbal teaching, which might hinder their cognitive development as well as make it difficult to coordinate between what they hear and process. Furthermore, the control group's lack of improvement might lead teachers to hold low academic expectations for children with hearing impairments, considering them as unnatural and interfering with their other classmates. Therefore, they may not observe them constantly to correct their mistakes, which might affect a child's level of learning in general. This finding is consistent with that of Oflantio and Gaustad (2002).

Results revealed improvements in both groups in the motor domain with no significant differences. This might be due to both groups receiving motor and sports activities in kindergarten. In addition, both groups showed improvement in the social/affective domain, but the improvement of the experimental group was higher. This might be due to the inclusion of children with hearing impairments into the non-disabled children's settings. This finding is consistent with that of River (2009), and Shaheen (2006) and Burgess (2005). Furthermore, the improvement of children in the experimental group on affective-social domain was greater than that of the control group. This might be because the experimental group children experienced a more unique achievement in the electronic games, which was reflected positively in the affective/social dimension. This finding is consistent with that of Subrah et al. (2001), Mohammad (2007) and Chang and Chen (2009).

The subjects' sex did not significantly influence the experimental group's level of performance. Games that were downloaded on the children's devices did not differ between the sexes. The nature of downloaded programs was general and had no specific characteristics that would create different mental thought-processes between sexes. This finding may reflect the lack of difference between them in the development of the social, motor and language skills, which also might explain the similarity between them.

It can be argued that iPad with the included games, aroused children with hearing impairments to use their mental, cognitive, and social abilities at a new level. They were focused and concentrated on the flow of information coming from the games, so their skills in acquiring information and their language developed. These findings were consistent with Awwad and Abdel-Rahman (2004).

\section{Recommendations}

In light of the results of the current study, the researcher strongly recommended the need for conducting more research studies to replicate these findings. There are no specialized studies in the Arab world and in Saudi society addressing the influence of the iPad on school preparedness for both children with hearing impairments and children without hearing impairments

It is recommended that the ministry of education to include this technology in teaching curriculums in order to increase learning levels for children with hearing impairments children during their different educational stages. This should begin at the kindergarten stage. Implementing this technology and these quality applications in the 
classroom, teachers can increase the success of their students with hearing impairments.

\section{Acknowledgments}

This is a research project that was supported by a grant from the Research Center for the Humanities, Deanship of Scientific Research at King Saud University.

\section{References}

Abdel-Wahed, M. 2001). Hearing disability and rehabilitation program. Al-Ein: Dar Al-Kitab Aljamei.

Abu-Ma'al, A. (1996). Developing language readiness in children. Amman:Al Amal for Publications.

Al- Qaryoti, I. (2002). Using computers in teaching the Arabic language for hearing-impairment children at UAE. Seventh Scientific Seminar for commission working in the care of deaf people (pp. 28-30). Al-Dawha.

Al-Hashmi, E., \& Abdel-Razzaq, Y. (2012). The influence of joining preschools in the development of reading and writing skills among basic stage female students in Jordan. Arabic childhood Journal,13(51), 8-30.

Alimam, M., \&Al-Abbadi, Z. (2010). The effectiveness of a program based on electronic games to develop creative thinking skills among deaf children. Educational and Psychological studies, Al-Zaqazeeg Education College Journal, 66, 207-262.

Al-Jaberi, N. (2011). Preschool child in the information technological age, childhood in a changing age conference. Amman: Petra University Press.

Al-Jawaldeh, F., \& Suhail, T. (2013). The effect of using educational games in developing some sport concepts among hearing-impairment children. Al-Quds open university journal, 1(3), 196-234.

Al-khateeb, J. (2002). Introduction to hearing disability. Dar Al-Fiker Publishers.

Al-Mehsen, M. (2003). Internet children; a study on the influence of internet on a child with a proposed educational program to deal with these effects. Education College Journal, 13(54), 134-164.

Awwad, A. \& Abdel-Rahman, M. (2004). The efficiency of using computer educational games to develop information classification skills among deaf children, Eleventh Amal Conference (Young people for a better future), Psychological counseling Journal, 2, 720-765.

Awwad, A. (1998). Working towards a scientific tool to rate school readiness for kindergarten children. Education Ein Shams, 22(1), 193-216.

Awwad, A. (1999). School readiness test for nursery and kindergarten children. Cairo: Dar Al Fiker.

Awwad, A. (2001). Learning readiness among the mentally-disabled at the preschool stage. Qatar: AlKhalaeej Al-Arabi University Press.

Baker, F. (1993). The relationship of intelligent and the degree of disability with deaf individuals, study achievement (Unpublished master thesis). Al-Zaqazeeq University, Egypt.

Burgess, C. (2005). The evaluation of a multi-component early intervention-childhood.

Chisholm, J., Hickey, C., Theeuwes, J., \& Kingstone, A. (2010). Reduced Attentional Capture in Action Video Game Players. Attention, Perception, \& Psychophysics, 72(3), 667-671. http://dx.doi.org/10.3758/APP.72.3.667

Couse, L., \& Chen, D. (2010). A tablet computer for young children? Exploring its viability for early childhood education. Journal of Research on Technology in Education, 43(1), 75-98. http://dx.doi.org/10.1080/15391523.2010.10782562

Eden, S. (2008). The Effect of 3D Virtual Reality on Sequential Time Perception among Deaf and Hard of Hearing Children. European Journal of Special Needs Education, 23(4), 349-363. http://dx.doi.org/10.1080/08856250802387315

Gaad, E., \& Qaryouti, I. (2002). Effect of using computers in teaching first grade deaf children in United Arab Emirates. Journal of Education UAEU, 17(19), 53-63.

Green, C., \& Bavelier, D. (2006). The Cognitive Neuroscience of Video Games. In P. Messaris, \& L. Humphreys, (Eds), Digital Media: Transformations in Human.

Halawah, M., \& Abdoh, B. (1996). Introduction to motor development science for children. Al-Riyadh: Arabic golf states educational office. 
Hanafi, A. (2003). Introduction to hearing disability. Al-Riyadh: Special education Academy.

Hatzigianni, A., \& Margetts, M. (2012). "I am Very Good at Computers", Young children's computer use and their computer self-esteem. European Early Childhood Education Research Journal, 20(1), 3-20.

Khasawneh, O., \& Al-Awidi, H. (2008). The effect of home computer use on Jordanian children: A parental perspective. Journal of Educational Computing Research, 39(3), 267-284. http://dx.doi.org/10.2190/EC.39.3.d

Marshark, M. (1997). Psychological development of deaf children. New York: Oxford University Press, Inc.

McClanahan, B. (2012). A breakthrough for josh: How use of an iPad facilitated reading improvement. TechTrends, 56(3), 20-28. http://dx.doi.org/10.1007/s11528-012-0572-6

Mohammad, A. (2007). Studies in exceptional psychology. Cairo: Dar Al-Rashad.

Mohammad, I., \& Mahmoud, N. (2003). School readiness and its relation with some variables in preschoolers. Al-Ma'arfah Journal, 20, 16-47.

Morsi, A. (2013). The efficiency of visual stimuli intensity in computer programs on school achievement and attitudes towards hearing-impairment students at the preparatory stage. Arabic studies in Education and Psychology, 42(2), 13-59.

Oflantio, M., \& Gaustad, M. (2002). Developing membership in the education of deaf and hard of hearing students in Inclusive Settings. Journal of Deaf Studies and Deaf Education, 7(3), 214-229. http://dx.doi.org/10.1093/deafed/7.3.214

Passig, D., \& Eden, S. (2000). Improving flexible thinking in deaf and hard of hearing children with virtual reality technology. American Annals of the Deaf, 145(3), 286-291. http://dx.doi.org/10.1353/aad.2012.0102

River, S. (2009). Early Childhood Special Education 0-8 Years: Strategies for positive outcomes. Pearson Education, 1.

Rosen, L., Whaling, K., Carrier, L., Cheever, N., \& Rokkum, J. (2013). The Media and technology usage and attitudes scale: An empirical investigation. Computers in Human Behavior, 29(6), 2501-2511. http://dx.doi.org/10.1016/j.chb.2013.06.006

Saleh, M. (2012). Giving preschool children with hearing-impaired children some logical thinking skills. Education Journal, Al-Azhar University, 1, 35-83.

Saleh, M. (2013). Our children and the knowledge world, $4^{\text {th }}$ International Conference entitled today's child is tomorrow's hope. Kindergarten College, 1, 165-180.

Shaheen, S. (2006). Early intervention and its role in qualifying deaf and hearing-impairment children for prospects: A field study of deaf children in kindergarten and in the special education institute for deaf children (Unpublished master thesis). Damascus University, Damascus.

Sharadgha, M. (2011). Efficiency of a computerized educational program for the development of expressive language skills among a sample of simple hearing-disable students at Irbid governorate (Unpublished $\mathrm{PhD}$ thesis). University of Jordan.

Sisalem, K. (2002). Special education and psychological rehabilitation encyclopedia. Cairo: Dar Al-Kitab Al-Jamie Publisher.

Spence, I., \& Feng, J. (2010). Video Games and Spatial Cognition. Review of General Psychology, 14(2), 92-104. http://dx.doi.org/10.1037/a0019491

Subrahmaryam, K., Greenfield, P., Kraut, R., \& Gross, E. (2001). The impact of computer use on children's and adolescents' development. Applied Developmental Psychology, 22, 7-30. http://dx.doi.org/10.1016/S0193-3973(00)00063-0

\section{Copyrights}

Copyright for this article is retained by the author(s), with first publication rights granted to the journal.

This is an open-access article distributed under the terms and conditions of the Creative Commons Attribution license (http://creativecommons.org/licenses/by/3.0/). 